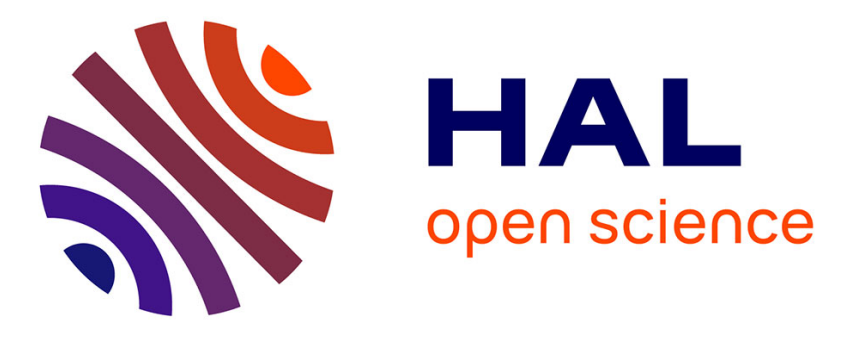

\title{
Experimental Bond Dissociation Energies of Benzylpyridinium Thermometer Ions determined by Threshold-CID and RRKM modeling
}

David Gatineau, Antony Memboeuf, Anne Milet, Richard B Cole, Héloïse

Dossmann, Yves Gimbert, Denis Lesage

\section{To cite this version:}

David Gatineau, Antony Memboeuf, Anne Milet, Richard B Cole, Héloïse Dossmann, et al.. Experimental Bond Dissociation Energies of Benzylpyridinium Thermometer Ions determined by ThresholdCID and RRKM modeling. International Journal of Mass Spectrometry, 2017, 417, pp.69-75. 10.1016/j.ijms.2017.03.002 . hal-03146746

\author{
HAL Id: hal-03146746 \\ https://hal.science/hal-03146746
}

Submitted on 19 Feb 2021

HAL is a multi-disciplinary open access archive for the deposit and dissemination of scientific research documents, whether they are published or not. The documents may come from teaching and research institutions in France or abroad, or from public or private research centers.
L'archive ouverte pluridisciplinaire HAL, est destinée au dépôt et à la diffusion de documents scientifiques de niveau recherche, publiés ou non, émanant des établissements d'enseignement et de recherche français ou étrangers, des laboratoires publics ou privés. 


\title{
Experimental Bond Dissociation Energies of Benzylpyridinium Thermometer Ions determined by Threshold-CID and RRKM modeling.
}

\author{
David Gatineau, ${ }^{1,3}$ Antony Memboeuf, ${ }^{2}$ Anne Milet, ${ }^{3}$ Richard B. Cole, ${ }^{1}$ Héloïse Dossmann,,${ }^{1}$ Yves \\ Gimbert, ${ }^{3}$ Denis Lesage ${ }^{1 *}$ \\ 1) Sorbonne Universités, UPMC Univ. Paris 06 and CNRS, IPCM (UMR 8232), F-75252 Paris \\ Cedex05, France
}

2) Univ. Bretagne Occidentale and CNRS, CEMCA (UMR 6521), F-29238 Brest, France

3) Univ. Grenoble Alpes and CNRS, DCM (UMR 5250), F-38000 Grenoble, France

\begin{abstract}
Benzylpyridinium salts (BPs) have often been used as thermometer ions to obtain an energy calibration of mass spectrometric experiments (in particular to determine internal energy distributions of ions after the ionization process). Fragmentation of $\mathrm{BP}^{+}$molecular ions is characterized by specific Bond Dissociation Energies (BDE) which depend on the substituent group and its location on the benzyl ring. Although those $\mathrm{BDE}$ values are regularly re-evaluated by quantum chemical calculations, their experimental determination is still missing from the literature. In this paper, a modified Quadrupole-hexapole-Quadrupole (QhQ) mass spectrometer is used to obtain such values on $4 \mathrm{BP}^{+}$molecular ions (characterized by a wide range of C-N bond strengths) using Threshold Collision-Induced Dissociations (TCID) and Rice-Ramsperger-KasselMarcus (RRKM) kinetic modeling. It is found that experimental values are systematically $0.5 \mathrm{eV}$ lower than their most recent theoretical evaluations. Despite this shift, the absolute critical energy values are maintained in the same order $(\mathrm{pOMe}<\mathrm{pMe}<\mathrm{pCl}<\mathrm{pCN})$, and the relative energy differences are in very good agreement. We argue that the observed $0.5 \mathrm{eV}$ shift relates to the energy dependence of the Transition State's number of states that is typical for barrier-less fragmentation processes and, relates to a kinetic rather than an energetic bottleneck. Notably, by taking into account the bond elongations characterizing the transition states and their corresponding calculated critical energies $\left(E_{0}\right)$, close agreement is found with experimentally obtained $E_{0}$ values. We thus conclude that much care should be taken when describing the transition state during an internal energy calibration procedure where the involved energy is lower than 3-4 eV.
\end{abstract}

\section{Introduction}

In addition to its many contributions to analytical applications, mass spectrometry is an established tool for fundamental chemical studies including kinetic and thermodynamic measurements. ${ }^{1,2}$ The use of low-energy Collision-Induced Dissociation (CID) as a means to measure bond energies is an active area of research. Using a "tandem-in-space" mass spectrometer, rigorous Threshold-CID (TCID) measurements can offer accurate thermodynamic data, provided that certain experimental conditions are fulfilled. ${ }^{3-5}$ For example, collision energies must be well defined, and the ions of interest must have well-characterized initial internal and kinetic energy distributions. Moreover, collision cross sections corresponding to single collision 
conditions should be analyzed. Various instrumental set-ups can be used for such endeavors, including dedicated mass spectrometers such as "Guided Ion Beam MS" (GIBMS) where energy-resolved data are acquired. Another efficient approach is by use of a modified "classical" tandem-in-space mass spectrometer such as a Quadrupole-hexapole-Quadrupole (QhQ), even though larger inaccuracies for absolute measurements of critical energy $\left(E_{0}\right)$ values can be expected compared to those obtained with GIBMS. Nevertheless, relative measurements (thereby giving $\Delta E_{0}$ values) can be made with great precision. For instance, the comparison of two competitive pathways using the kinetic method, or the comparison of fragmentations of different precursor ions characterized by a similar size have already been performed with a QhQ mass spectrometer. ${ }^{6}$

Benzylpyridinium salts (BPs) are typically used as thermometer ions to obtain a calibration of an energization process in mass spectrometric experiments (e.g. to determine internal energy distributions of ions after the ionization process). Fragmentation of $\mathrm{BP}^{+}$molecular ions is characterized by specific Bond Dissociation Energies (BDE) which depends on the electronic properties of the substituent group and its location on the benzyl ring (Scheme 1). ${ }^{7}$ A range of theoretical values has been proposed for the critical energies corresponding to this direct cleavage ${ }^{8-13}$ (or alternatively for more complex rearrangement processes). ${ }^{14-18}$ Using quantum chemical calculations, those BDE values are regularly re-evaluated by increasing the level of electronic description, thereby allowing for energy calibrations with increasing accuracy. However, experimental determination of BDE of such compounds is still absent from the literature. ${ }^{13}$ In this paper, a modified QhQ mass spectrometer is used to obtain such values using TCID and RRKM (Rice-Ramsperger-Kassel-Marcus) kinetic modeling. ${ }^{19-22}$ To support the work presented in the current paper, the most recent calculations will be used, including the transition state determination. ${ }^{13}$

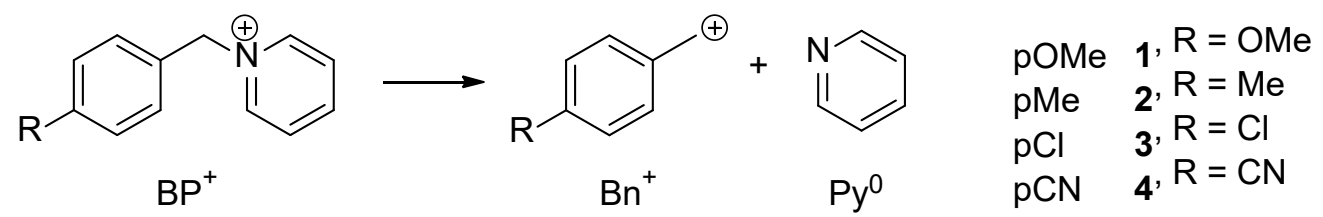

Scheme 1. Dissociation pathway of benzylpyridinium ions used in this study.

\section{Material and methods}

\subsection{Sample preparation}

Four chloro p-substituted benzylpyridinium salts, (BPs), were prepared according to the literature (pOMe, $\mathrm{pMe}, \mathrm{pCl}, \mathrm{pCN}$ ) (Scheme 1). They were dissolved in methanol to obtain a final solution concentration of 1 $\mu \mathrm{g} / \mathrm{mL}^{7}$

\subsection{Mass spectra analysis}

Electrospray ionization (ESI) mass spectra and TCID spectra were recorded using a modified Quattro II Quadrupole-hexapole-Quadrupole mass spectrometer (Micromass, Manchester, UK) that has been previously described. ${ }^{23,24}$ An illustration of the modified apparatus is shown in Figure 1. Mass spectral data were acquired using Masslynx software (version 4.2, Micromass). Desolvated $\mathrm{BP}^{+}$ions were obtained using 
a capillary voltage of $2.9 \mathrm{kV}$, a source temperature of $100^{\circ} \mathrm{C}$ and nitrogen as the desolvation and nebulizing gas. All other source parameters were maintained constant throughout the complete set of experiments. Keeping Q1 static, the $\mathrm{BP}^{+}$ions were mass-selected by Q1. In the hexapole $\mathrm{h} 2$, the collision energy was varied from 1 to $40 \mathrm{eV}$ (in the laboratory frame) and the product ion spectra were obtained by scanning Q3 between $\mathrm{m} / \mathrm{z} 10$ and 230. Argon or Xenon was used as the collision target gas, and the collision cell pressure was maintained between $4 \times 10^{-6}$ mbar and $1.8 \times 10^{-4}$ mbar (Penningvac PR 25) using an external micrometric valve (all-metal regulating valve UDV 040) with a customized line added directly to the region of the collision cell.

Figure 1. Schematic diagram of the modified triple quadrupole mass spectrometer used to perform ESITCID experiments.

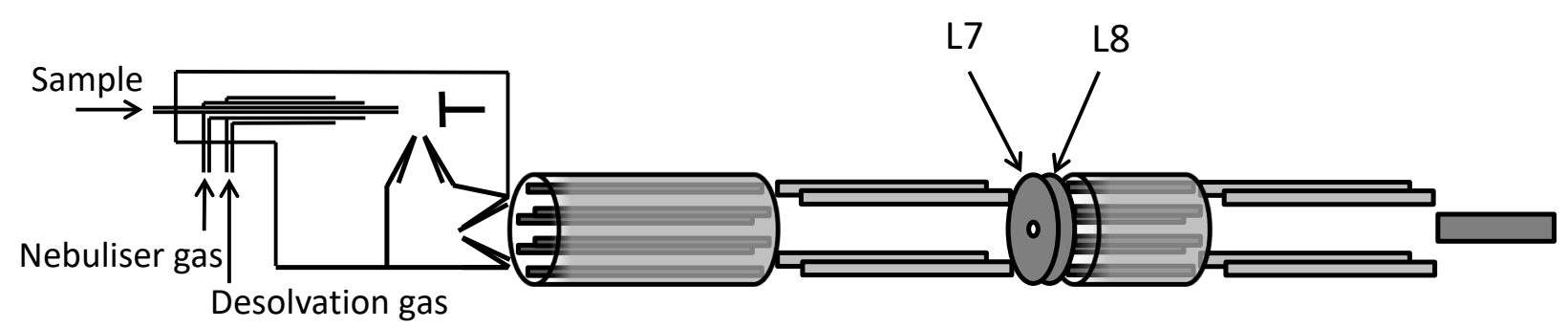

\section{Z-spray ESI source}

h0

Q1

h2

Q3

D

\begin{tabular}{l|l|l|l|l|l}
\hline & & $\begin{array}{l}\text { Transfer } \\
\text { hexapole }\end{array}$ & $\begin{array}{l}\text { Quadrupole } \\
\text { Ion selection }\end{array}$ & Collision cell & Quadrupole + detector \\
\hline $\begin{array}{l}\text { MassKinetics } \\
\text { Modeling description }\end{array}$ & Ion formation & Field-free flight & $\begin{array}{l}\text { Electrostatic } \\
\text { acceleration } \\
\text { Field-free flight } \\
\text { ion selection }\end{array}$ & $\begin{array}{l}\text { Electrostatic } \\
\text { acceleration } \\
\text { collision cascade } \\
\text { electrostatic } \\
\text { acceleration }\end{array}$ & ion detection \\
\hline Length (cm) & & $\mathbf{2 8}$ & $\mathbf{2 5}$ & $\mathbf{1 5}$ & $\mathbf{2 5}$ \\
\hline $\begin{array}{l}\text { Cone voltage (V) } \\
\text { Polarization (V) }\end{array}$ & $\mathbf{1 5}$ & & $\mathbf{0 . 5}$ & $\mathbf{0}$ \\
\hline Collision voltage (V) & & & & 1 to 40 & \\
\hline Pressure (mbar) & & & & $\begin{array}{l}4.0 \times 10^{-6} \text { to } \\
1.8 \times 10^{-4}\end{array}$ & \\
\hline
\end{tabular}

Bold characters are used for fixed parameters and italic characters are those which may vary or which are intentionally modified

\subsection{Modeling details}

Electronic structures and frequencies calculations were performed using Density Functional Theory (DFT) ${ }^{25}$ at the BMK/BSI level according to the theoretical procedure described by DeBord et al. ${ }^{13}$ Geometrical cross sections $(S)$, necessary for modeling collisional processes, were determined using the minimum energy conformers obtained from DFT calculations as described above with the Sigma program ${ }^{26-28}$ compiled for Windows that was provided to us by $\mathrm{T}$. Wyttenbach. Van der Waals atomic radii were used from crystallographic data reported by Batsanov ${ }^{29}$ except for hydrogen atoms, for which the default value was used. Buffer gases Van der Waals radii, Ar and Xe, were taken from values reported by A. Bondi. ${ }^{30}$ It must be noted, however, that those values are underestimated according to recent theoretical estimations. ${ }^{31}$ In order to confirm the validity of atomic parameters used, geometrical cross sections for $3 \mathrm{BP}^{+}$ions were computed and compared with those obtained experimentally by Morsa et al. ${ }^{32}$ Results obtained with Batsanov's parameters slightly improved $S$ values as compared with those derived using default atomic radii. The same procedure was then used to compute geometrical cross sections for all $\mathrm{BP}^{+}$ions. 
Kinetic modeling of TCID experiments was performed using MassKinetics ${ }^{33}$ Scientific Demo software (version 1.16: http://www.chemres.hu/ms/masskinetics/). This software was previously successfully used to simulate CID experiments ${ }^{34}$; it relies on a master equation approach combining a detailed description of energization during the collisional events with the RRKM kinetic theory to account simultaneously for fragmentation. It is noteworthy that $\mathrm{Crunch}^{35}$, and L-CID ${ }^{36}$ software programs are more dedicated programs for TCID measurements. Thus, Crunch allows the possibility to use an orbiting transition state and hindered rotors to describe direct cleavage processes. L-CID allows a simplification of the procedure when the number of degrees of freedom becomes larger than a few dozen. These two software programs allow the possibility of introducing an initial kinetic energy distribution, and they also provide a more relevant description of ion-neutral collision processes. On the other hand, MassKinetics, which is used for this study, is more easily available, and is perhaps more intuitive and easier to combine with a detailed description of the geometry of the mass spectrometer used. In particular, it allows the treatment of multicollisional processes, as well as taking into account the decomposition of the precursor ion in the Q3 analyzer, when using a triple quadrupole. This "late" decomposition may greatly distort results, especially when a large kinetic shift is occurring. In this case, the precursor ion is decomposed in the Q3 analyzer but the fragment ions are not detected. ${ }^{37}$ However, as mentioned by Ervin and Armentrout ${ }^{38}$, Crunch and MassKinetics give similar results because both programs use accurate computational algorithms.

In the latter simulations, the geometry of the mass spectrometer and the polarization of the multipoles were set equal to their experimental values (indicated in bold characters in Table 1). A number of important physical parameters can be adjusted prior to performing the kinetic modeling. Experimental conditions, such as the nature and pressure of the collision gas, and the collision voltage in $\mathrm{h} 2$ (indicated in italic characters) were varied as shown in Table 1. Furthermore, in order to determine the critical energy of fragmentation, which constitutes the main interest of this study, several molecular parameters are needed. Among them, ground state and transition state harmonic oscillator frequencies were used in the simulation (determined by DeBord et $a l.) .{ }^{13}$ All other parameters requiring adjustment/optimization are discussed in the following section.

\section{Results and discussion}

To obtain reliable data from TCID experiments, attention and care must be given to several important parameters. The most critical are the initial internal and kinetic energies of the reactant ions, the ion abundance-to-collision cross section conversion, the effect of the specific collision gas partner, and the background correction. Each of these is discussed separately and in detail in the following sections. Different models to determine activation energies for all four $\mathrm{BP}^{+}$ions are then presented and discussed.

Briefly for TCID measurements, decomposition is expected to occur mainly in the collision cell owing to uptake of internal energy upon collision of selected precursor $\mathrm{BP}^{+}$ions with a neutral monoatomic target gas. Our procedure consists of the following steps: after having determined the initial internal energies of surviving precursor ions, energy-resolved MS/MS data are acquired and plotted in a reactive cross-section $v s$. center-of-mass frame kinetic energy diagram accounting for pressure and nature of neutral target gas as well as molecular size contributions. Those data are then modeled using Masskinetics software allowing for fitting of experimental data using different collisional energy transfer functions, and finally to determine critical energies of interest.

\subsection{Initial Internal and Kinetic Energies of precursor ions}


The success of TCID measurements depends heavily on accurate knowledge of the initial internal and kinetic energies of the precursor ions entering the collision cell. Electrospray-generated ions are generally considered to have a low-level of internal energy upon desorption, but their internal energies may be augmented by raising the difference of potential between the "cone" and subsequent "skimmer", such that formed ions accelerate and collide with residual gas in this intermediate pressure region. ${ }^{37,39,40}$

To assess this effect, ESI source temperature, cone voltage and pressure of nitrogen in h0 were varied in the following ranges: $30-100{ }^{\circ} \mathrm{C}, 10-50 \mathrm{~V}$ and $4 \times 10^{-4}-3 \times 10^{-3}$ mbar. Within this range of conditions, we were not able to observe any changes in the CID spectra. Clearly, precursor ions are stable and thermalized prior to entering the first quadrupole, allowing us to reasonably hypothesize Maxwell-Boltzmann distributions $^{23}$ for internal energy of molecular ions. Thus, results obtained do not depend on ESI source parameters, but rather, on the temperature of $\mathrm{N}_{2}$ gas in $\mathrm{h} 0$ that is $300 \mathrm{~K}$.

\subsection{Conversion of ion abundances into cross sections and effect of collision partner.}

The pressure of the neutral gas in the collision cell was maintained constant below $1.8 \times 10^{-4}$ mbar in order to limit multiple collisions while energy-dependence curves were obtained for the four $\mathrm{BP}^{+}$ions. The neutral gas is considered to be in a stationary state, ${ }^{41}$ and the ions are arriving with a kinetic energy, $E_{\text {lab }}$ in the laboratory frame of reference, defined by the voltage applied to h2. The maximum energy transferred during a single collision is defined by the center-of-mass energy $E_{\mathrm{CM}}=E_{\text {lab }} \mathrm{m} /(\mathrm{m}+\mathrm{M})$, where $\mathrm{m}$ and $\mathrm{M}$ are the masses of the neutral gas and $\mathrm{BP}^{+}$ion, respectively. Thus, a higher target gas mass will lead to a higher maximum energy transferred during a single collision.

The collision process between an ion and a neutral gas will have an associated reaction cross-section, $\sigma_{c o l}$ and can be thought of as the effective area that the reactants present to one another such that a collision may occur. ${ }^{4}$ When the probability of collisions is small, raw ion abundances can be converted to experimental cross sections according to equation $1,{ }^{41}$

$\sigma_{c o l}=\left[I_{P} /\left(I_{P}+I_{R}\right)\right]\left(k_{B} T / P l\right)$

where $I_{P}$ is the product ion's abundance, $I_{R}$ is reactant (precursor) ion's abundance, $k_{B}$ is the Boltzmann constant, $l$ is the length of the collision cell, and $T$ is the temperature of the neutral gas. Calculations of absolute cross sections using data obtained from a QhQ mass spectrometer will be subject to certain errors. Indeed, measurements of pressures with a Penningvac gauge are only accurate to within $30 \%$, and the effective cell length cannot be easily evaluated because it requires comparison with absolute cross sections of test systems measured by other energy resolved experiments. ${ }^{4}$ The evaluation of reactive cross sections (equation 1) allows one to perceive the effect of pressure on the dissociation energy at the threshold for decomposition. At higher pressures, in contrast to the situation for single collision conditions, the distribution of reactant ions' energies resulting from multiple collisions is not well defined. The result is that more energy can be deposited at the same laboratory energy, thereby causing the apparent threshold for product formation (decomposition) to shift to lower energies. This effect is clearly evidenced in the inset of Figure 2 showing a shift of the curves to lower $E_{C M}$ as the pressure is raised. 


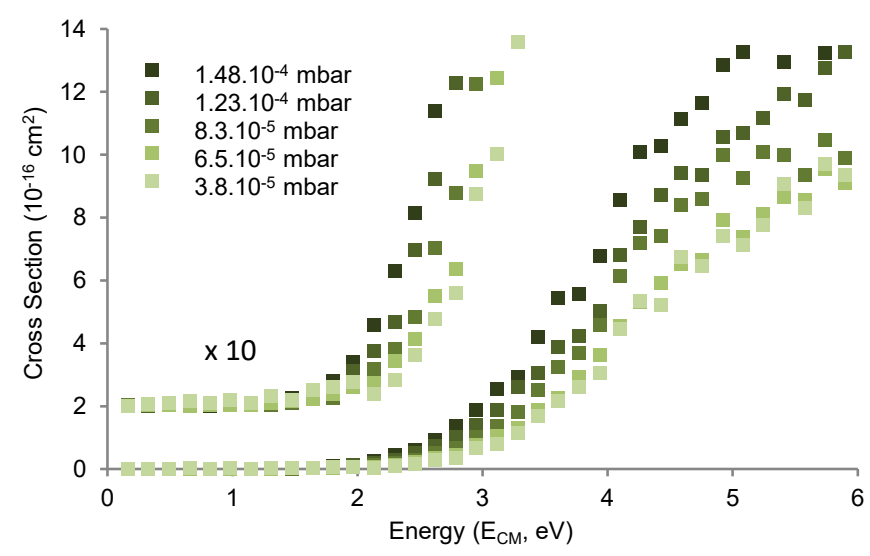

Figure 2. Pressure dependence of experimental cross section for TCID of $\mathrm{pCl} 3$ with $\mathrm{Ar}$ as a function of center-ofmass energy at five different corrected pressures $P_{\text {corr }}$ of $1.48 \times 10^{-4}, 1.23 \times 10^{-4}, 8.3 \times 10^{-5}, 6.5 \times 10^{-5}$, and $3.8 \times 10^{-5}$ mbar.

Note that, at the same $E_{C M}$, the calculated threshold values are the same no matter which neutral gas is used. Nevertheless, the collision partner can affect the collision induced dissociation efficiency, even when data are compared in the center-of-mass frame of reference. Thus, Xe-induced dissociation is more efficient at higher collision energy compared to Ar-induced dissociation, as shown in Figure 3. Despite this advantage, a problem related to the use of $\mathrm{Xe}$ as target gas is that accurate pressure measurement was not possible using our Penningvac gauge. We were able to obtain an estimation of the pressure after calibration with a labile gold complex that is susceptible to complete decomposition (See supporting information for detail).
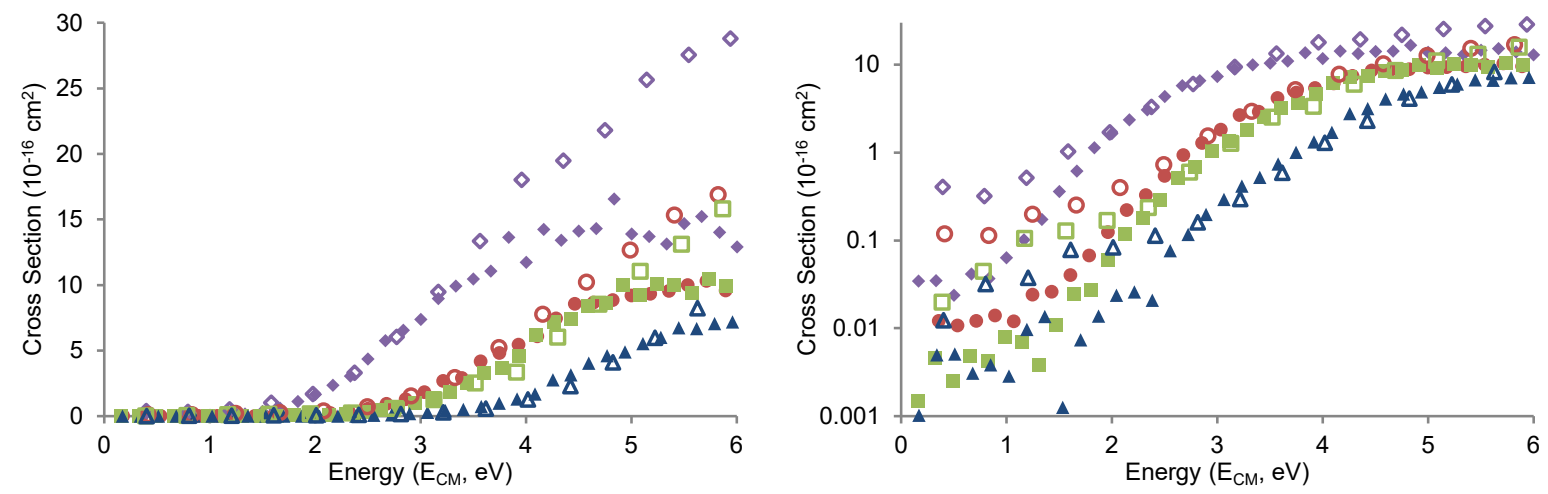

Figure 3. Experimental cross section as a function of center-of-mass energy for TCID of pOMe 1 (purple diamonds), pMe 2 (red circles), $\mathrm{pCl} 3$ (green squares) and $\mathrm{pCN} 4$ (blue triangles) with different rare gas collision partners: Ar (solid symbols) and Xe (hollow symbols).

\subsection{Background correction}

Quadrupole and electrostatic lens biases were adjusted in order to minimize dissociation processes occurring outside the collision cell. The polarization of Q1 and the voltage of lens L8 were maintained at $0.5 \mathrm{~V}$ and 5 $\mathrm{V}$, respectively, in order to allow efficient transmission of selected ions without changing kinetic energy before entering the h2 collision cell (Figure 1). Variation of the L7 voltage did not affect the dissociation reaction, and no polarization was applied to Q3. Moreover a lower quadrupole resolution was used in order to increase ion transmission. 
Any contribution to product ion abundances resulting from decompositions occurring outside the collision cell (thereby creating a type of background noise) needs to be taken into account when measuring TCID values. Contrary to what is done in GIBMS experiments, background correction is not obtained by introducing the gas directly into the vacuum chamber. Because of the rather high pressure of $\mathrm{N}_{2}$ in $\mathrm{h} 0$ and a residual pressure of $2 \times 10^{-5}$ mbar in the $\mathrm{h} 2$ collision cell, introduction of Ar at very low pressure inside the collision cell and surrounding chambers did not perceptibly affect product ion abundances. This result suggests that background fragmentation is due to collisions with residual $\mathrm{N}_{2}$. So, the background curve was recorded by measuring the product and reactant ions' abundances with Ar directed into the $\mathrm{h} 2$ collision cell, but at the lowest pressure necessary to replace background $\mathrm{N}_{2}$ originating from the ESI source with Ar in the collision cell (3.2 × $\left.10^{-5} \mathrm{mbar}\right)$. Under these conditions, background noise and product ion abundances resulting from decomposition reactions occurring outside the collision cell can be explicitly measured and later subtracted from the signals obtained with gas directed into the cell. The pressure of $3.2 \times 10^{-5} \mathrm{mbar}$ corresponding to a minimum pressure of gas inside the collision cell was thus subtracted from the pressure reading on the penningvac gauge in all subsequent experiments to give a corrected pressure $P_{\text {corr. }}$. In the case of Xe used as target gas, the $\mathrm{N}_{2}$ contribution in energy-resolved CID curves can be neglected and no background corrections were performed.

In the CID experiments presented herein, the pressure in the collision cell is high enough so that small variations in pressure will lead to non-negligible changes in measured $E_{0}$. Thus, for each $\mathrm{BP}^{+}$ion, energydependence curves were recorded at five different pressures for collisions with Argon with subtraction of the background curve. All data are presented in supporting information.

\subsection{Determination of critical energy $E_{0}$ (MassKinetics modeling)}

By using a master equation approach, MassKinetics software enables the modeling of TCID experiments by considering the instrument geometry and by accounting simultaneously for the collisional excitation and molecular fragmentation processes. After having included the instrument geometry in our model (Figure 1), molecular parameters (size and vibrational modes of ground and transition states structures) were obtained by using the Sigma program and DFT calculations, to finally let only the critical energy $E_{0}$, associated with the dissociation process, to be determined. Concerning kinetic and internal energies of $\mathrm{BP}^{+}$precursor ions, their initial values were fixed to $300 \mathrm{~K}$ (cf. preceding section) and allowed to increase by considering collisional activation with an inert gas by using an energy transfer function (in our model the function proposed by Muntean \& Armentrout ${ }^{42}$ ) to depict the efficiency of energy transfer from kinetic to internal (by using the parameter $\eta$ ). Experimental reactive cross sections $v s$. $E_{C M}$ diagrams were then fitted using two different models.

In the first approach, both $E_{0}$ and $\eta$ were optimized to achieve the best fits of all experimental TCID data at each pressure. The corresponding dissociation energy values, denoted $E_{\eta}(A r)$, are reported in Table 1, whereas the corresponding calculated and experimental curves are presented in Figure 4. From these results, two principal trends are deduced: 1$) E_{\eta}$ is almost constant $( \pm 0.05 \mathrm{eV})$ no matter what pressure of argon is employed, and 2) efficiencies appear to decrease (from 0.215 to 0.14 ) when the pressure is raised. In this modeling, the dissociation energy $E_{\eta}$ seems to be independent of the collision gas pressure, and the critical energy, $E_{0}$, can thereby be directly derived without extrapolation to zero pressure.

In our second model, the efficiency $\eta$ was fixed at a medium value of 0.18 and dissociation energies, denoted $E_{0.18}$, were adjusted in order to obtain the best simulation of experimental curves. As shown in Figure 4, 
larger differences between experimental and calculated curves are observed especially for the higher energies $\left(\mathrm{E}_{\mathrm{CM}}>3 \mathrm{eV}\right)$ and the higher pressures. In this approach, dissociation energy, $E_{0.18}$, is linearly correlated to Ar pressure and the extrapolation to zero pressure leads to the critical energy $E_{0}$. It is worth noting that for these simulations the average number of collisions is calculated to be 0.66 at $1.48 \times 10^{-4} \mathrm{mbar}$ (highest pressure used), which corresponds to $14 \%$ of the precursor ion population undergoing multiple collisions.
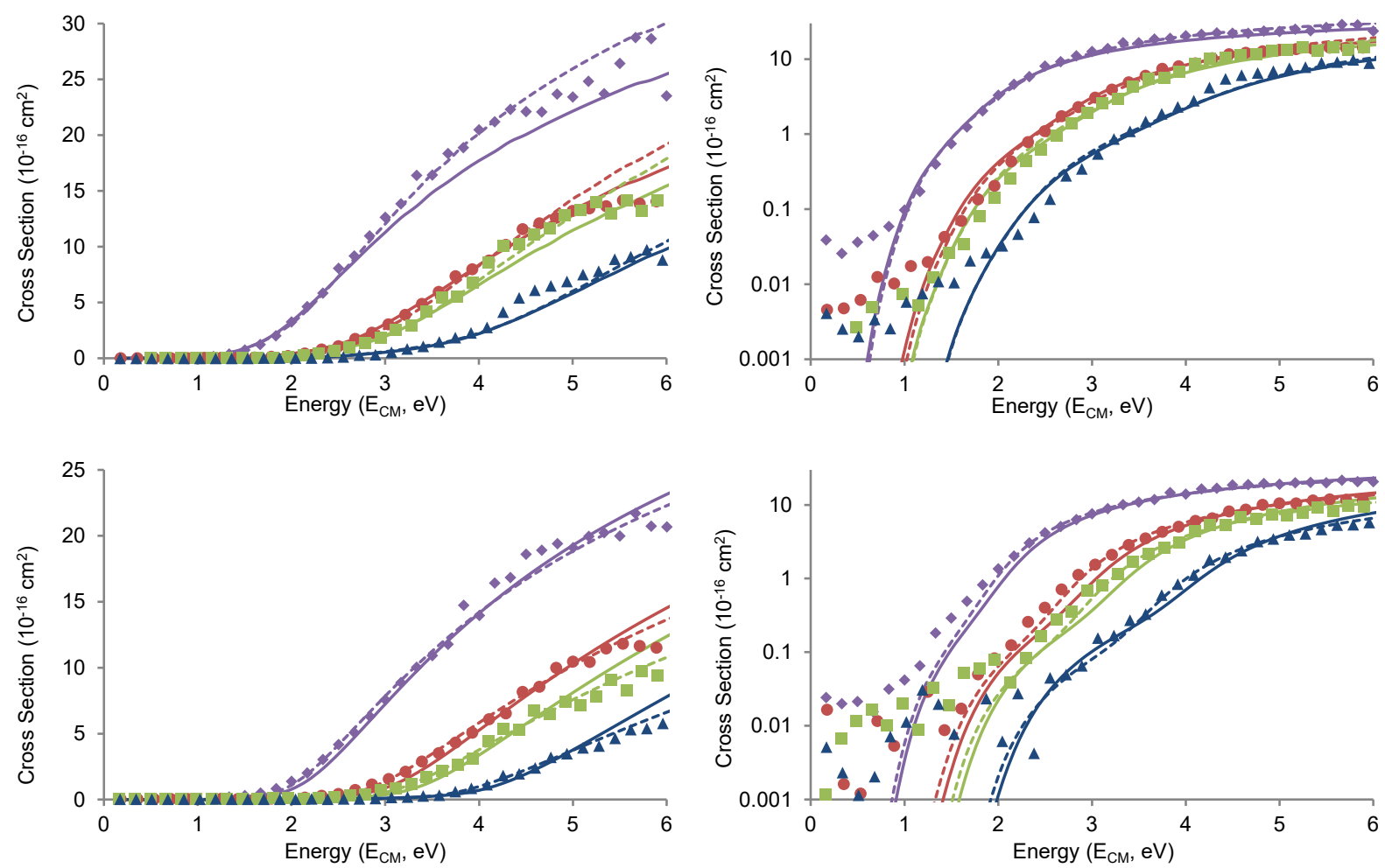

Figure 4. Experimental cross sections for TCID of pOMe 1 (purple diamonds), pMe $\mathbf{2}$ (red circles), pCl 3 (green squares) and pCN 4 (blue triangles) with Ar as a function of center-of-mass energy at $1.48 \times 10^{-4} \mathrm{mbar}$ (top) and $3.8 \mathrm{x}$ $10^{-5} \mathrm{mbar}$ (bottom). The dashed lines correspond to variable efficiency curves. The solid lines correspond to a fixed efficiency $\eta$ of 0.18 .

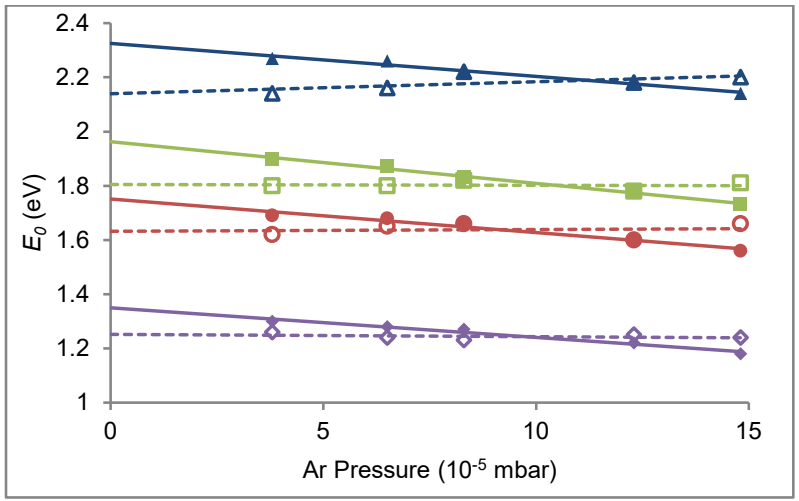


Figure 5. Dissociation critical energies $E_{\eta}$ (hollow symbols) and $E_{0.18}$ (solid symbols) of pOMe 1 (purple diamonds), pMe 2 (red circles), $\mathrm{pCl} 3$ (green squares) and $\mathrm{pCN} 4$ (blue triangles) as a function of Ar pressure with adjustable efficiencies $\eta$ and fixed efficiencies at 0.18 in MassKinetics software-and their linear regressions (dashed line and solid line, respectively)

The same kinetic modeling was performed on energy-resolved CID data using Xe as the collision gas. The best fits were obtained using similar MassKinetics parameters despite changes in the pressure, and these employed parameters resembled those used for Ar. The efficiency was fixed at $0.195\left(E_{0.195}\right)$ and measured critical energies, $E_{0}$, were found to be quite close for the two different pressures. Curve fitting gave lower quality results in the threshold region compared to those obtained from collisions with Ar. This deterioration could be at least partially explained by the absence of background subtraction. Experimental and modeling results are presented in Figure 6.
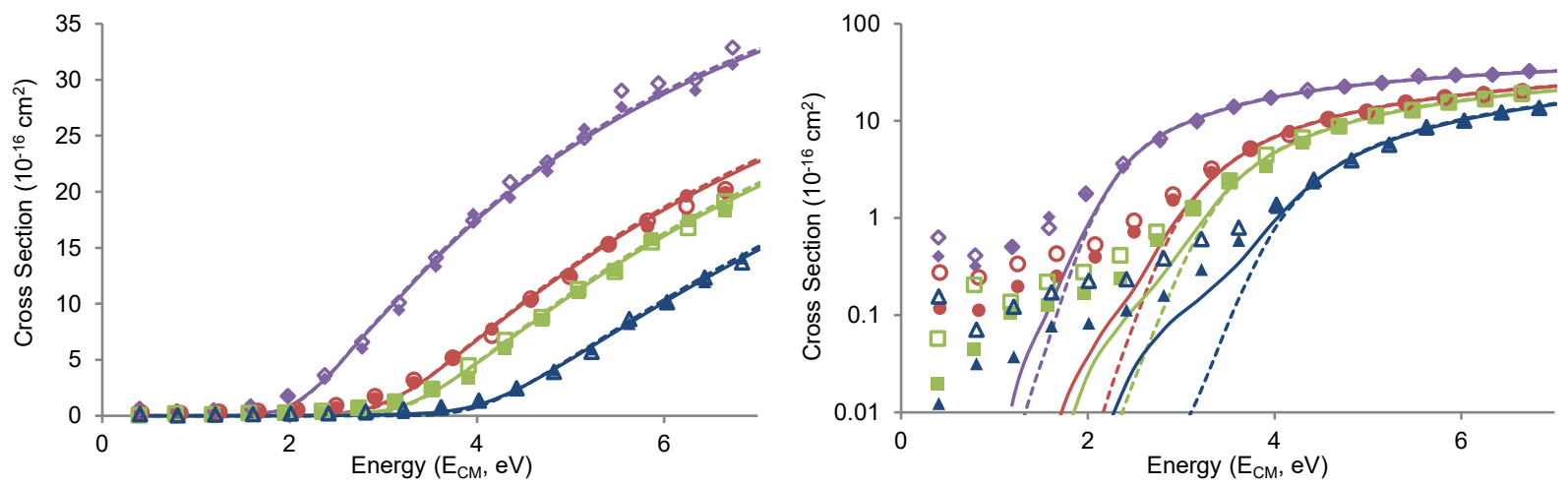

Figure 6. Experimental cross section for TCID of pOMe $\mathbf{1}$ (purple diamonds), pMe $\mathbf{2}$ (red circles), $\mathrm{pCl} \mathbf{3}$ (green squares) and $\mathrm{pCN} 4$ (blue triangles) with Xe as a function of center-of-mass energy at $1.6 \times 10^{-5} \mathrm{mbar}$ (solid markers) superimposed on $4 \times 10^{-6}$ mbar (hollow markers). The lines show the simulation model for $1.6 \times 10^{-5} \mathrm{mbar}$ (dashed lines) and $4 \times 10^{-6} \mathrm{mbar}$ (solid lines).

\subsection{Assessment of uncertainties in critical energy values}

Experimental critical energies obtained for $\mathrm{BP}^{+}$ions are reported in Table 1. As expected, it appears that the collision partner has almost no effect on measured critical energies; moreover, the three experimental approaches give virtually the same relative difference of $E_{0}$ between the $4 \mathrm{BP}^{+}$ions $\left(\Delta E_{0}\right)$. For example, experimental values of $\Delta E_{0}(4-1)$ vary from $0.89 \mathrm{eV}$ to $0.97 \mathrm{eV}$. Moreover, these relative $\Delta E_{0}$ measurements are in very good agreement with calculated BDE values for $\Delta E_{0}(4-1)$ that varied from $0.9 \mathrm{eV}$ to $0.92 \mathrm{eV}$ according to the employed level of calculation.

Table 1. Calculated BDE and experimental critical energies for $\mathrm{BP}^{+}$ions

\begin{tabular}{cccc|ccc}
\hline Pyridium salt & $\begin{array}{c}\text { BDE, }{ }^{13} \mathrm{eV} \\
\mathrm{CCSD}(\mathrm{T})\end{array}$ & $\begin{array}{c}\text { Calculated } \\
B D E,{ }^{13} \mathrm{eV}\end{array}$ & $\begin{array}{c}\text { Ecal. }(x \AA) \mathrm{eV}^{a} \\
\mathrm{BMK} / \mathrm{BSI}\end{array}$ & $\begin{array}{c}E_{0}(\mathrm{Ar}), \mathrm{eV}^{b} \\
(\eta=0.18)\end{array}$ & $\begin{array}{c}\text { Experimental } \\
E_{\eta}(\mathrm{Ar}), \mathrm{eV}^{b} \\
\text { (adjustable } \eta)\end{array}$ & $\begin{array}{c}E_{0}(\mathrm{Xe}), \mathrm{eV}^{b} \\
(\eta=0.195)\end{array}$ \\
\hline pOMe 1 & $\mathbf{1 . 8 4}$ & $\mathbf{1 . 7 1}$ & $\mathbf{1 . 2 6}(1.2 \AA)$ & $\mathbf{1 . 3 5}( \pm 0.11)$ & $\mathbf{1 . 2 5}( \pm 0.11)$ & $\mathbf{1 . 3 1}( \pm 0.21)$ \\
pMe 2 & $\mathbf{2 . 2 7}$ & $\mathbf{2 . 1 2}$ & $\mathbf{1 . 6 2}(1.4 \AA)$ & $\mathbf{1 . 7 5}( \pm 0.14)$ & $\mathbf{1 . 6 3}( \pm 0.14)$ & $\mathbf{1 . 7 0}( \pm 0.24)$ \\
pCI 3 & $\mathbf{2 . 3 7}$ & $\mathbf{2 . 2 6}$ & $\mathbf{1 . 7 5}(1.4 \AA)$ & $\mathbf{1 . 9 6}( \pm 0.14)$ & $\mathbf{1 . 8 0}( \pm 0.14)$ & $\mathbf{1 . 8 8}( \pm 0.23)$ \\
pCN 4 & $\mathbf{2 . 7 4}$ & $\mathbf{2 . 6 3}$ & $\mathbf{2 . 0 7}(1.6 \AA)$ & $\mathbf{2 . 3 2}( \pm 0.16)$ & $\mathbf{2 . 1 4}( \pm 0.16)$ & $\mathbf{2 . 2 5}( \pm 0.26)$ \\
$\Delta E_{0} \mathbf{( 4 - 1 )}$ & $\mathbf{0 . 9 0}$ & $\mathbf{0 . 9 2}$ & $\mathbf{0 . 8 1}$ & $\mathbf{0 . 9 7}( \pm 0.09)$ & $\mathbf{0 . 8 9}( \pm 0.09)$ & $\mathbf{0 . 9 4}( \pm 0.06)$ \\
\hline
\end{tabular}


${ }^{a}$ Calculated energy of $\mathrm{BP}^{+}$ions after elongation of the C-N bond corresponding to the estimated transition state; ${ }^{b}$ Uncertainties are given in brackets

Uncertainties on critical energies were estimated by variation of molecular parameters, collision parameters and energy deposition as follows: a) The ground-state oscillator frequencies and transition state oscillator frequencies were varied by $\pm 10 \%$ in order to take the contribution of uncertainties on vibrational frequencies calculations; b) The initial internal energy was varied from 250 to $350 \mathrm{~K}$; c) An uncertainty of $\pm 20 \%$ was applied on the efficiency ( $\eta$ ); d) A shift of $E_{l a b}= \pm 2 \mathrm{eV}$ of the collision energy was estimated; e) The uncertainty of the collision cell pressure is about $\pm 30 \%$. The total standard deviation of the critical energy determination is the root-sum-of-squares of the critical energy standard deviations obtained by variation of all these parameters.

It must be mentioned, that obtained experimental values of $E_{0}$ are systematically under-estimated by approximately $0.5 \mathrm{eV}$ compared to the calculated BDEs. This non-negligible difference is unexpected, and it deserves some comment. Several hypotheses may be advanced to explain this discrepancy: i) a highenergy tail exists in the kinetic energy distribution, ii) the initial internal energy was somehow higher than estimated, iii) the employed model is too simplistic to accurately describe of the interaction of an ion and a neutral during collision, iv) the employed description of the transition state was inappropriate.

Gerlich has shown that the distribution of kinetic energies of ions in a gas-filled RF multipole can have a high energy tail when the gas pressure is high and the multipolar order is too low. ${ }^{43}$ Thus, TCID measurements require at least a hexapole collision cell, thereby excluding "true" triple quadrupole mass spectrometers equipped with quadrupole collision cells. ${ }^{3}$ This type of energy tail would produce an artificially low critical energy which could potentially explain the observed shift of $-0.5 \mathrm{eV}$ for measured critical energies. To address this possibility, we performed retarding potential measurements in order to obtain the kinetic energy distribution in the collision cell (see supporting information). The retarding potential experiments show no significant tail at high energies. The MassKinetics software does not allow the input of a Gaussian curve as a kinetic energy distribution and only an average kinetic energy value or a temperature can be used. However, the use of a kinetic energy distribution of $5800 \mathrm{~K}$ (close to the Gaussian distribution derived from the retarding potential curve) slightly modifies the value of the measured critical energy (around $0.02 \mathrm{eV}$ see Supporting Information). Due to the difficulty of obtaining a precise retarding potential curve (only nominal values of $E_{l a b}$ can be used), this kinetic energy distribution has not been integrated into the simulations using MassKinetics.

The simplest explanation for this difference of $0.5 \mathrm{eV}$ would be to consider a high initial internal energy (around $700 \mathrm{~K}$ instead of $300 \mathrm{~K}$ ). However, this hypothesis is not plausible because of the high pressure in the h0 hexapole which thermalizes the precursor ions and eliminates the effect of employed source parameters (in particular, the collisional heating near the skimmer). This hypothesis would also lead to a rapid divergence between experimental and calculated curves (see Supporting Information).

The use of a "hard spheres collision cross-section" $\left(\sigma_{\mathrm{HS}}\right)$, which is independent of the collision energy, is not the most adequate model to describe the interaction of an ion with a neutral. However, this value is a required input value in MassKinetics, in contrast to Crunch software which proposes a more accurate and thorough description of the phenomena where the long-range attractive ion-induced dipole potential pulls the colliding partners together. ${ }^{44}$ So the use of "Langevin-Gioumousis-Stevenson cross section" $\left(\sigma_{\mathrm{LGS}}\right)$ which depends on the energy and the polarizability volume of the neutral is more adequate for energies 
below $1 \mathrm{eV}$ where $\sigma_{\mathrm{LGS}}$ is higher than $\sigma_{\mathrm{HS}}$ (at higher energies $\sigma_{\mathrm{LGS}}$ is lower than $\sigma_{\mathrm{HS}}$ ). ${ }^{41,45}$ Thus, for the higher energies, the fact that $\sigma_{\mathrm{LGS}}$ is lower than $\sigma_{\mathrm{HS}}$ would result in higher $E_{0}$, which goes in the opposite direction and cannot explain the observed shift of $0.5 \mathrm{eV}$ to lower energy.

For $\mathrm{BP}^{+}$ion fragmentation, the transition state is defined by a loose transition state and after elongation of the C-N bond, DeBord et al. have located this transition state for pOMe 1, pMe 2, pCl 3 and pCN 4 at a C$\mathrm{N}$ bond distance of $1.2 \AA, 1.4 \AA, 1.4 \AA$ and $1.6 \AA$, respectively for an internal energy of $5.95 \mathrm{eV}$. For the current paper, using MassKinetics, the rate constants $\mathrm{k}(\mathrm{E})$ were calculated for the four $\mathrm{BP}^{+}$ions along the fragmentation pathway at different internal energies (from $2.5 \mathrm{eV}$ to $9 \mathrm{eV}$, see $\mathrm{SI}$ ). The rate constant is given by equation 3 :

$k(E)=W^{*}\left(E-E_{0}\right) / h \rho(E)(3)$

where $W^{*}\left(E-E_{0}\right)$ is the sum of states of the transition state between 0 and $E-E_{0}$ range, $h$ is Planck's constant and $\rho(E)$ is the density of states of the ground state molecular ion at an internal energy $E$. It is noteworthy that, at $6 \mathrm{eV}$ internal energy, minima of $\log (\mathrm{k} . \mathrm{s})$ curves are observed for $\mathrm{C}-\mathrm{N}$ bond elongations close to those observed by DeBord et al. for pOMe 1, pMe 2, pCl 3 (See SI), corresponding to the transition state of the dissociation pathway. For lower energies, corresponding to those involved for our TCID experiments, such minima are still observed for pOMe $\mathbf{1}$ and $\mathrm{pCl} \mathbf{3}(3-5 \mathrm{eV})$, but clearly they are not present for pMe $\mathbf{2}$ for internal energy lower than $4 \mathrm{eV}$. The case of pCN 4 is more complex because the appearance of two negative frequencies does not allow the calculation for elongations higher than $1.6 \AA$ and also results in missing points on the curves. Nevertheless, minima are observed at 7 and $8 \mathrm{eV}$. Thus, for the pCN 3 ion, the procedure proposed by DeBord et al. was used to calculate the sum of states of the transition state. Similar results were obtained for $6 \mathrm{eV}$ leading to a minimum at around $1.65 \mathrm{eV}$ which was shifted to $1.75 \mathrm{eV}$ for 5 $\mathrm{eV}$, but for lower energy no minima were observed between 1.6 and $2 \AA$. In conclusion, the calculated transition states defined at $6 \mathrm{eV}$ are not adequate for the lowest internal energies. This result partly explains the poor fit of the curves for low internal energies and a further study of Variational RRKM or perhaps orbiting transition state would probably produce better results.

At this stage, the energies of $\mathrm{BP}^{+}$ions corresponding to the transition states (Ecal. $(x \AA) ; x=1.2 \AA, 1.4 \AA$, $1.4 \AA$ and $1.6 \AA$ for pOMe 1, pMe 2, pCl 3 and pCN 4, respectively), calculated at the BMK/BSI level, are reported in Table 1. These calculated values are in good agreement with the experimentally-determined critical energies, and it suggests that even if a loose transition state is presumed to exist, the transition state relates to a kinetic, rather than an energetic, bottleneck and, may explain in large part, the difference observed between the experimentally measured critical energies and the calculated energies of reaction.

\section{Conclusion}

Experimental $E_{0}$ determinations of benzylpyridinium ions were performed for the first time by TCID measurements and RRKM modeling. Such experiments were performed on a "classical" QhQ mass spectrometer and key parameters were carefully controlled in order to acquire high precision data to be modeled efficiently using MassKinetics software. The comparison of experimental values with DFT calculations reveals a shift downwards by $0.5 \mathrm{eV}$ for all experimentally determined critical energies. This shift, however, does not affect relative critical energy values, thereby respecting the order obtained in 
calculations: $\mathrm{pOMe}<\mathrm{pMe}<\mathrm{pCl}<\mathrm{pCN}$. Moreover, the absolute differences between values obtained experimentally agree very well with theoretical value differences. A possible explanation for the $0.5 \mathrm{eV}$ shift is that among the various possible transition states, those of the highest energies appear to differ the most from the final product states characterized by complete dissociations. These higher energy transition state species may thus yield $E_{0}$ values that diverge the most from calculated BDE's. These results, obtained for $\mathrm{BP}^{+}$probes, confirm that the use of a commercial QhQ enables relative measurements of critical energies for dissociation to be obtained with very good precision, although GIBMS experiments would definitely improve absolute critical energy values.

\section{ACKNOWLEDGMENT}

ANR is acknowledged for financial support (fellowship for DG).

Wei Xin is acknowledged for preliminary trials during her fellowship.

The research team of J. D. DeBord is acknowledged for helpful discussions concerning the calculation of the sum of states.

\section{References:}

1. Armentrout, P. B. Int. J. Mass Spectrom. 2015, 377, 54-63.

2. Rodgers, M. T.; Armentrout, P. B. Chem. Rev. 2016, 116 (9), 5642-5687.

3. Armentrout, P. B. Int. J. Mass Spectrom. 2000, 200 (1-3), 219-241.

4. Armentrout, P. B. J. Am. Soc. Mass Spectrom. 2002, 13 (5), 419-434.

5. Angel, L. A.; Ervin, K. M. J. Phys. Chem. A 2004, 108 (40), 8346-8352.

6. Bourgoin-Voillard, S.; Afonso, C.; Lesage, D.; Zins, E. L.; Tabet, J. -C.; Armentrout, P. B. J. Am. Soc. Mass Spectrom. 2013, 24 (3), 365-380.

7. Derwa, F.; De Pauw, E.; Natalis, P. Org. Mass Spectrom. 1991, 26 (2), 117-118.

8. Gabelica, V.; De Pauw, E.; Karas, M. Int. J. Mass Spectrom. 2004, 231 (2-3), 189-195.

9. Gabelica, V.; De Pauw, E. Mass Spectrom. Rev.2005, 24 (4), 566-587.

10. Barylyuk, K. V.; Chingin, K.; Balabin, R. M.; Zenobi, R. J. Am. Soc. Mass Spectrom. 2010,21 (1), $172-177$.

11. Rondeau, D.; Galland, N.; Zins, E. L.; Pepe, C.; Drahos, L.; Vekey, K. J. Mass. Spectrom. 2011,46 (2), $100-111$.

12. Morsa, D.; Gabelica, V.; De Pauw, E. Anal. Chem. 2011, 83 (14), 5775-5782.

13. DeBord, J. D.; Verkhoturov, S. V.; Perez, L. M.; North, S. W.; Hall, M. B.; Schweikert, E. A. J. Chem. Phys. 2013, 138 (214301).

14. Katritzky, A. R.; Watson, C. H.; Degaszafran, Z.; Eyler, J. R. J. Am. Chem. Soc. 1990, 112 (7), $2471-2478$. 
15. Zins, E. L.; Pepe, C.; Rondeau, D.; Rochut, S.; Galland, N.; Tabet, J. -C. J. Mass. Spectrom. 2009, 44 (1), 12-17.

16. Zins, E. L.; Pepe, C.; Schroder, D. J. Mass. Spectrom. 2010, 45 (11), 1253-1260.

17. Morsa, D.; Gabelica, V.; Rosu, F.; Oomens, J.; De Pauw, E. J. Phys. Chem. Lett. 2014, 5 (21), 3787-3791.

18. Huang, Y.; Yoon, S. H., Heron, S. R.; Masselon, C. D.; Edgar, J. S.; Tureček, F.; Goodlett, D. R. J. Am. Soc. Mass Spectrom. 2012, 23, 1062-1070.

19. Rice, O. K.; Ramsperger, H. C. J. Am. Chem. Soc. 1927, 49, 1617-1629.

20. Kassel, L. S. J. Phys. Chem. 1928, 32 (2), 225-242.

21. Marcus, R. A.; Rice, O. K. J. Phys. Colloid Chem. 1951, 55 (6), 894-908.

22. Marcus, R. A. J. Chem. Phys. 1952, 20 (3), 359-364.

23. Ichou, F.; Lesage, D.; Machuron-Mandard, X.; Junot, C.; Cole, R. B.; Tabet, J. -C. J. Mass. Spectrom. 2013, 48 (2), 179-186.

24. Lesage, D.; Milet, A.; Memboeuf, A.; Blu, J.; Greene, A. E.; Tabet, J. -C.; Gimbert, Y. Angew. Chem., Int. Ed. 2014, 53 (7), 1939-1942.

25. Parr, R. G.; Yang, W., Density-Functional Theory of Atoms and Molecules (Oxford University Press, 1994).

26. Von Helden, G.; Hsu, M. T.; Kemper, P. R.; Bowers, M. T. J. Chem. Phys. 1991, 95, 3835.

27. Von Helden, G.; Hsu, M. T.; Gotts, N.; Bowers, M. T. J. Phys. Chem. 1993, 97, 8182.

28. Wyttenbach, T.; Von Helden, G.; Batka, J. J.; Carlat, D.; Bowers, M. T. J. Am. Soc. Mass Spectrometry 1997, 8, 275.

29. Batsanov, S. S. Inorg.Materials 2001, 37, 871.

30. Bondi, A. J. Phys. Chem. 1964, 68, 441.

31. Rahm, M.; Hoffmann, R.; Ashcroft, N. W. Chem. Eur. J. 2016, 22, 14625.

32. Morsa, D. J. Am. Soc. Mass Spectrom. 2014, 25, 1384-1393

33. Drahos, L.; Vekey, K. J. Mass. Spectrom. 2001, 36 (3), 237-263.

34. Lesage, D.; Memboeuf, A.; Gimbert, Y.; Tabet, J. -C. Int. J. Mass Spectrom. 2012, 319, 31-39.

35. Rodgers, M. T.; Armentrout, P. B. Mass Spectrometry Reviews, 2000, 19, 215-247

36. Narancic, S.; Bach, A.; Chen, P. J. Phys. Chem. A 2007, 111, 7006-7013

37. Pak, A.; Lesage, D.; Gimbert, Y.; Vekey, K.; Tabet, J.-C. J. Mass. Spectrom. 2008, 43 (4), 447-455.

38 Ervin, K. M.; Armentrout, P. B. J. Mass Spectrom. 2004, 39, 1004-1015

39. Naban-Maillet, J.; Lesage, D.; Bossee, A.; Gimbert, Y.; Sztaray, J.; Vekey, K.; Tabet, J. -C. J. Mass. Spectrom. 2005, $40(1), 1-8$. 
40. Rondeau, D.; Drahos, L.; Vékey, K. Rapid Commun. Mass Spectrom. 2014, 28, 1273-1284

41. Armentrout, P. B. J. Anal. At. Spectrom. 2004, 19 (5), 571-580.

42. Muntean, F.; Armentrout, P. B. Journal of Chemical Physics 2001, 115 (3), 1213-1228.

43. Gerlich, D. Adv. Chem. Phys. 1992, 82, 1-176.

44. Pauly, Atom-Molecule Collision Theory, Bernstein, Ed., Plenum, New York, 1979, 127.

45. http://rodgers.chem.wayne.edu/pire/education/Collision induced \%20dissociation_PIRE.pdf. 